preceded the Mid-Pleistocene revolution at 0.9 myr when the boreal ice sheet increased in size and the prevailing glacial cyclicity changed from $\sim 40 \mathrm{kyr}$ to $\sim 100 \mathrm{kyr}$.

Before the Quaternary, $\delta^{13} \mathrm{Cmax}$ usually occurred at times of minimal eccentricity forcing, and the long term-variations in $\delta^{13} \mathrm{C}$ and $\delta^{18} \mathrm{O}$ display the same $400 \mathrm{kyr}$ cycles; but in the Quaternary, $\delta^{13} \mathrm{Cmax}-\mathrm{Il}$ and $\delta^{13} \mathrm{Cmax}$-III are out of phase with this astronomical cycle (Fig.1). Therefore, prior to the formation of large ice sheets in the Northern Hemisphere, $\delta^{13} \mathrm{C}$ co-varied with $\delta^{18} \mathrm{O}$ in the ocean records but in Quaternary times the 400-kyr cyclicity waned in the $\delta^{18} \mathrm{O}$ records and apparently "stretched" into 500 kyr in $\delta^{13} \mathrm{C}$.

The origin of the $\delta^{13} \mathrm{Cmax}$ episodes in the Quaternary and the nature of the long-term cycles remain unclear. Our working hypothesis suggests that the long-term cycles in weathering intensity in tropical areas may give rise to increased flux of Si from land to ocean, which may change the diatom/coccolith ratio in phytoplankton and subsequently the organic/inorganic carbon ratio in sediments. There is strong evidence for the 400-kyr cyclicity in monsoon climate and in opal production in the ocean that is well-correlated with the $\delta^{13} \mathrm{C}$ record. However, more work is needed to find out the mechanism behind the observed changes in carbon cycling. A common practice in Quaternary climate history studies is just to peruse ice-volume variations as exhibited by $\delta^{18} \mathrm{O}$, by considering carbon system changes as the consequences of ice-volume changes. The new discovery shows that long-term changes in carbon reservoirs on the Earth have their own periodicity and their own history, and do not simply follow ice cap variations in the Northern Hemisphere. The Quaternary period has passed through three major stages defined by four $\delta^{13} \mathrm{Cmax}$ events, and each appears to represent a further step in icecap development. Now the Earth is passing through a new carbon isotope maximum, $\delta^{13} \mathrm{Cmax}-\mathrm{I}$. It is therefore crucial to understand the physical and climatic significance of the long-term carbon cycles, if we are to predict the natural long-term changes of global climate.

\section{REFERENCES}

Wang P, Tian J, Cheng X, Liu, C., Xu, J., 2003. Carbon reservoir change preceded major ice-sheets expansion at Mid-Brunhes Event. Geology, 31: 239-242.

Wang P, Tian J, Cheng X, Liu, C., Xu, J., 2003. Exploring cyclic changes of the ocean carbon reservoir. Chinese Science Bulletin, 48: 2536-2548.

Wang P, Tian J, Cheng X, Liu, C., Xu, J., 2004 Major Pleistocene stages in a carbon perspective: The South China Sea record and its global comparison. Paleoceanography, 19, PA4005, dio: 10.1029/2003PA000991

\title{
A 1437-year Precipitation History From Qilian Juniper in the Northeastern Qinghai-Tibetan Plateau
}

\author{
Xuemei Sha0 ${ }^{1,2}$, Eryuan Liang ${ }^{2}$, Lei Huang ${ }^{1}$ and Lily Wang ${ }^{1,2}$ \\ IInstitute of Geographical Sciences and Natural Resources Research, CAS, Beijing 100101, China; shaoxm@igsnrr.ac.cn \\ ${ }^{2}$ Institute of Tibetan Plateau Research, CAS, Beijing 100085, China
}

High-resolution proxy records of climate spanning multiple millennia are needed to understand natural climate variability of the past. The native Qilian juniper (Sabina przewalskii) growing in the mountains of arid and semi-arid areas in the northeastern Qinghai-Tibetan Plateau exhibits a great potential for climate reconstruction. Based on well-replicated and cross-dated specimens from living trees from 11 sites (Fig. 1) at Delingha, Wulan and Tianjun, Qinghai Province, a 1600-year-long regional composite ring-width chronology was developed. This chronology was compared with the Dulan chronology (Zhang, et al., 2003), which is located approx. 65-150 km south of our sites. It was found that there were two more rings in our chronology than in the Dulan chronology in the common interval of AD 404-2000. One ring occurred at either AD 874 or 875, and another one at AD 711, rather than at AD 682 as indicated

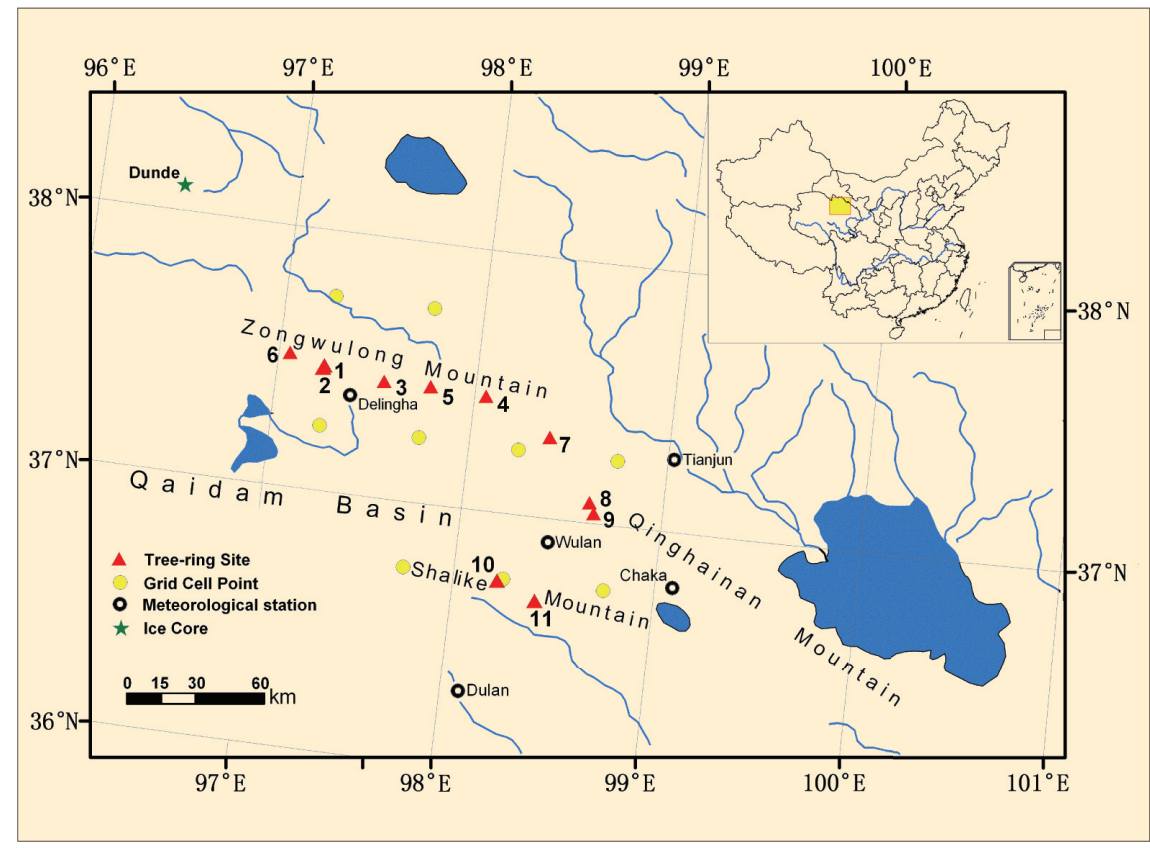

Fig. 1: Location of tree-ring sites, grids of precipitation data and meteorological stations.

by Tarasov et al. (2003) and Sheppard et al. (2004). Besides the reconstruction of past climate as reported here, this multi-site chronology will serve as the master chronology to cross-date archeological specimens excavated from tombs of the Tubo Kingdom in Delingha County, a potential that has been demonstrated by Sheppard et 


\section{Science Highlights: China}

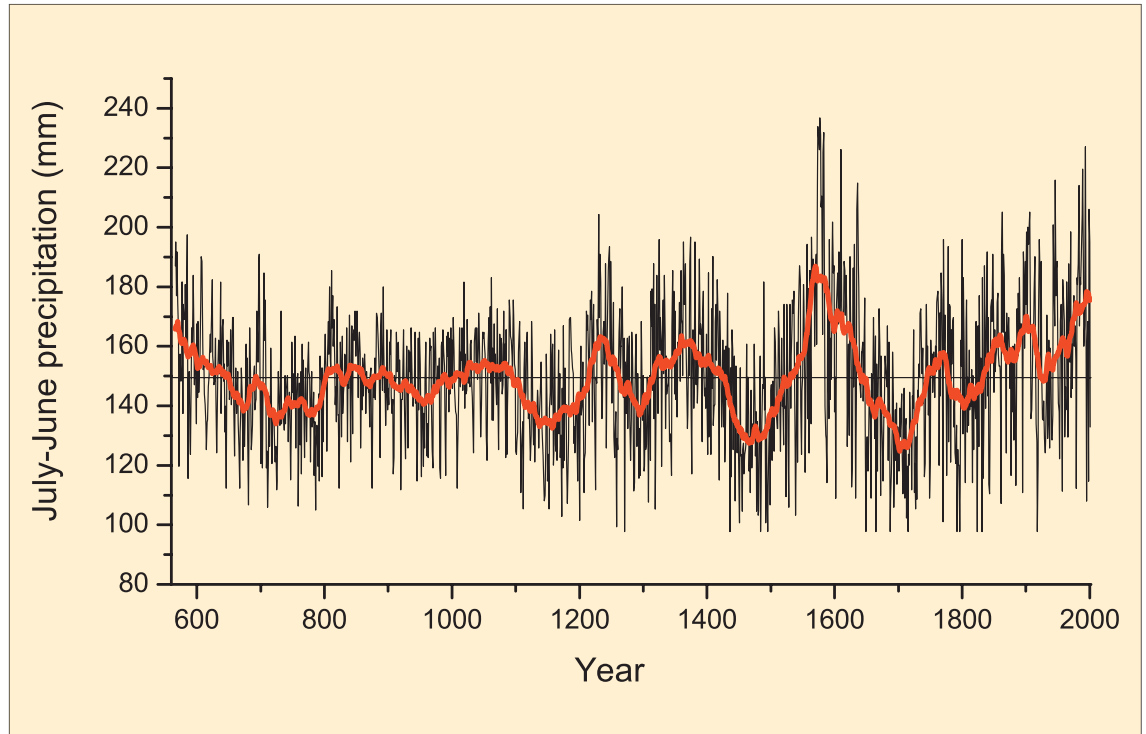

Fig. 2: Precipitation reconstructions. The 31-year running means (red) and long-term mean (horizontal line) are also shown.

al. (2004), who also reconstructed precipitation but using material from fewer sites.

In developing the regional chronology $(\mathrm{RC})$, samples with more than 1,050 rings, and with good correlation with the mean series from each site were selected. Negative exponential or linear regression models with negative coefficients were used to fit and remove the growth trend. The sample depth of the $\mathrm{RC}$ is 6 cores from 5 trees in $A D$ 566, 9 cores from 7 trees in AD 700, 22 cores from 16 trees in AD 800 and more than 50 cores from 36 trees in AD 900. Based on the subsample signal strength of 0.85 , the chronology was truncated at AD 566 for the climate reconstruction. The average length of cores is 803 years, indicating that the chronology should capture decadal- up to centennial-scale variability.

In our preliminary study (Shao et al., 2004), we found that Qilan juniper growth in the study area was mainly limited by moisture conditions in May and June and that a significantly positive correlation was found between the $\mathrm{RC}$ and the total precipitation from July of the previous year to June of the current year. Therefore, the annual precipitation summed from July of the previous year to June of the current year was reconstructed. The climate data we used were from CRUTS 2.1, available at www. cru.uea.ac.uk. In order to make the climate data more regionally representative, monthly precipitation data from $90.5^{\circ} \times 0.5^{\circ}$ gridpoints (Fig. 1) were averaged into a regional dataset. Since the effect of low precipitation on tree growth is more profound than that of high precipitation in the arid area, the precipitation series was transformed into a logarithmic scale. The calibration model explained $65 \%$ of the variance in the calibration period 1955-2002, and the correlation coefficient was 0.79 for the cross-validation. The reduction of error, product means test and sign test statistics also support the validity of the model. Since the correlation coefficient of July-June precipitation with January-December precipitation could even reach 0.95 after the 5-year running mean was performed for both series, it is clear that low frequency variability in the reconstructed precipitation series can very well represent the variations of the instrumental record.

The 1,437-year reconstruction of precipitation (Fig. 2) is characterized as follows:

1. Climate in the calibration period was relatively moist in the context of the past 1,437 years; only during the period $A D$ 1563-1590 was annual precipitation higher than the present.

2. Dramatic oscillations of precipitation occurred during the
Little Ice Age. Before AD 1400, the magnitude of variation in annual precipitation was about $15 \mathrm{~mm}$ but it was up to $30 \mathrm{~mm}$ during the period of 1400-1750. After 1750, the magnitude of variation decreased. The most pronounced wet intervals centered around the late 16th century, and the most severe and prolonged dry periods occurred in the late $15^{\text {th }}$ century and early $18^{\text {th }}$ century. These two dry periods corresponded to the Spoerer and Maunder sunspot minima, respectively.

3. Compared with the Little lce Age, variations in the low frequency domain of precipitation during the Medieval Warm Period were less dramatic, and the variance in the high frequency domain was also low in the period 800 1200. A decreasing trend was observed in the period 566-800.

4. Spectral analysis indicated that the reconstructed precipitation contained significant low frequency (150-250 years) cycles. The 200-year period was indicated clearly in the Little Ice age by wavelet analysis and singular spectrum analysis.

\section{REFERENCES}

Shao, X., L. Huang, H. Liu, E. Liang, X. Fang and Wang, L., 2004: Reconstruction of precipitation variation from tree rings in recent 1000 years in Delingha, Qinghai, Science in China Ser. D, 34(2): 145-153(in Chinese)

Sheppard, P.R., Tarasov, P.E., Graumlich, L.J., Heussner, K.-U., Wagner, M., Oesterle, H. and Thompson, L.G., 2004: Annual precipitation since 515 BC reconstructed from living and fossil juniper growth of northeastern Qinghai Province, China, Climate Dynamics 23: 869-881.

Tarasov, P., Heussner, K.U, Wagner M. and Wang, S. 2003: Precipitation changes in Dulan 515 BC-800 $A D$ inferred from tree-ring data related to the human occupation of NW China, Eurasia Antiqua, Band 9: 303-321.

Zhang, O.-B., Cheng, G., Yao, T., Kang, X. and Huang, J., 2003: A 2,326-year tree-ring record of climate variability on the northeastern Qinghai-Tibetan Plateau. Geophysical Research Letters, Vol. 30(14), 1739, doi: 10.1029/2003GL017425. 